\title{
The European Centre for Disease Prevention and Control launches a public consultation. Send your comments!
}

A Kanellopoulou (Athanasia.Kanellopoulou@ecdc.europa.eu) ${ }^{1}$, A Jansen ${ }^{1}$

1. European Centre for Disease Prevention and Control (ECDC), Stockholm, Sweden

Citation style for this article:

Kanellopoulou A, Jansen A. The European Centre for Disease Prevention and Control launches a public consultation. Send your comments!. Euro Surveill. 2012;17(28):pii=20219. Available online: http://www.eurosurveillance.org/ViewArticle.aspx?Articleld=20219

Article submitted 12 July 2012 / published on 12 July 2012

The European Centre for Disease Prevention and Control (ECDC) is launching a public consultation today on the draft technical report entitled Prevention of norovirus infection in schools and childcare facilities.

The draft technical report synthesises current international recommendations and review findings related to the prevention and control of gastroenteritis outbreaks in schools and childcare facilities. The focus is on norovirus, which is one of the most common causes of childhood gastroenteritis and is characterised by high rates of infectivity and transmission. Furthermore, the report seeks to identify the key facts that can support message development for the implementation of health communication activities in childcare settings.
The purpose of the consultation is to give members of the scientific community, as well as all other interested stakeholders, the opportunity to provide their comments on the draft document, in a spirit of openness and transparency.

The draft technical report, as well as relevant information on how to submit comments to ECDC can be found on the ECDC website: http://ecdc.europa.eu/ en/publications/Publications/Forms/ECDC_DispForm. aspx?ID=923.

Interested parties are invited to provide their written comments by 31 August 2012. 